\title{
Retrospective Study On Rift Valley Fever in Selected States in Sudan With Reference to Spatial and Animal Patterns
}

Mohamed Elsadig Mansour ( $\square$ mohamedalsadiq@cvrlsudan.gov.sd)

Central Veterinary Research Laboratory

Tamador mohamed Abdellah

Central Veterinary Research Laboratory

Selma Kamal

Central Veterinary Research Laboratory

Atif Alamin Abdelgadir

University of Khartoum

\section{Research}

Keywords: Retrospective, RVF, seroprevalence, spatial and animal patterns, risk factors, Sudan

Posted Date: June 10th, 2020

DOI: https://doi.org/10.21203/rs.3.rs-25177/v1

License: (c) (i) This work is licensed under a Creative Commons Attribution 4.0 International License. Read Full License 


\section{Abstract \\ Background}

A retrospective study was performed in selected states of the Sudan that include Gezira state, White Nile, Blue Nile, Khartoum, River Nile and Sennar states in order to investigate the seroprevalence of Rift Valley Fever (RVF) from 2007 to 2016. The risk factors that identified for RVF were locality, species, and animal population. For example, locality and species were significantly associated with seroprevalence of RVF (P-value $=049)(P$-value $=0.000)$ respectively, While animal population was not associated in Gezira state $(P$-value $=.415)$ and $\chi^{2}$ value was (12.629), however it was significantly associated in other regions. The highest seroprevalence estimated for RVF was $0.7 \%$ in River Nile state, while lowest seroprevalence for RVF recorded was $0.01 \%$ in Khartoum and Sennar states, respectively.

\section{Methods}

The current study was carried out in selected states in Central Sudan to investigate the epidemiology of RVF. Also it was focused on livestock in particular sheep, goat and cattle. Study design was retrospective to investigate seroprevalence, risk factors and spatial and animal patterns associated with RVF from 2007 to 2016.

\section{Result}

Estimated seroprevalence of RVF was $0.15 \%(n=905)$ in sheep, $0.20 \%(n=776)$ in goats and $0.13 \%(n=638)$ in cattle respectively. The risk factors that identified for RVF were locality, species, and animal population. For example, locality and species were significantly associated with seroprevalence of RVF $(P$-value $=049)(P$-value $=0.000)$ respectively, While animal population was not associated in Gezira state $(P$-value $=.415)$. Environmental risk factors i.e. annual temperature and annual rain fall were compared to RVF occurrence in study area with average mean of $29.0^{\circ} \mathrm{C}$ and $398.8 \mathrm{~mm}$

\section{Conclusion}

Rift valley fever is arthropod-born zoonosis disease. It affects livestock like sheep, goat, cattle and camel .it usually occurs following heavy rainfall and cause storm of abortion in pregnant animals. The principle vector of RVF is Mosquitoe and also it is transmitted through tissues of infected animal and human and also through of undercooked milk. In spite of there is no confirmed cases that can be transmitted from person to person by direct contact. It is characterized in human by influenza- like illness, in moderate cases can develop retinitis and eye infection and severe complication can cause hemorrhagic form with oozing of blood from natural orifices, the morbidity and mortality rate is varying from $5-100 \%$ in livestock, death rate can reach up to $10 \%$ and case fatality rate is less than one percent. The vaccination against RVF is used in case of outbreak and suspected cases in livestock; however there is no available vaccine for human usage. The current study is retrospective survey to investigate the seroprevalence, risk factor and spatial and animal patterns in selected states in Sudan. Estimated seroprevalence of RVF was $0.15 \%(n=905)$ in sheep, $0.20 \%(n=776)$ in goats and $0.13 \%(n=638)$ in cattle respectively. The risk factors that identified for RVF were locality, species, and animal population. For instance, locality and species were significantly associated with seroprevalence of RVF (P-value $=049)$, (P-value $=0.000)$ respectively, While animal population was not associated in Gezira state $(P$-value $=.415)$. Environmental risk factors i.e. annual temperature and annual rain fall were compared to RVF occurrence in study area with average mean of $29.0^{\circ} \mathrm{C}$ and $398.8 \mathrm{~mm}$ respectively.

\section{Introduction}

Rift Valley fever (RVF) is arthropod-borne viral zoonosis disease. It affects small ruminants, sheep and goats, and large ruminants like cattle and camel, and also can affect human. Rift Valley Fever virus (RVFV) belongs to the family Bunyviridae, genus Phlebovirus. The first isolation of RVFV was done in Kenya (2). RVFV is a negative sense RNA virus. The principle vector of RVF is mosquitoes and midges. It is characterized by storm abortion in pregnant animals, following heavy rain falls season. It is influenza like illness in human and can exceed that to cause retinitis and eyes infection in patient who are diagnosed with RVF infection. Also, in severe cases could development hemorrhagic fever form and oozing of blood from natural orifices RVF is reported in Sudan in Kosti in 1977 whereas involved human and animal cases, and spread across River Nile up to Khartoum. The morbidity and mortality rates are ranging from 5 to $100 \%$ in pregnant animals and death rate reach up to $10 \%$ and case fatality rate is less than one percent. This study was retrospective study to analyze previous information available for RVF and using it in planning for early warning system and contingency planning and preparedness

Page $2 / 12$ 
strategies for prevention and control of the disease in present and future point in time. Also the current study was to estimate the seroprevalence in study area , Gezira , Khartoum , Blue Nile, White Nile, River Nile and Sennar, determine the spatial and temporal patterns of the disease in Sudan.

\section{Objective}

This paper is aimed to understand Rift valley fever epizootiology in selected states of Sudan and evaluate spatial and temporal patterns which are considered as important to explain the distribution of the disease by designing geographical maps for disease in previous years and investigate the risk factors associated with RVF occurrence.

\section{Material And Method}

\section{Study area}

The current study was investigated Rift Valley Fever susceptible localities in the Sudan. White Nile, Gizera, Blue Nile, Khartoum and Sennar States were surveyed, (Figure 1).

\section{Study population}

The study was focus on livestock population in Sudan with special emphasis on most susceptible species for Rift Valley Fever like small ruminants (sheep and goats), as well as cattle.

\section{Study design}

Retrospective study design was carried out to investigate, sero-prevalence, associated risk factors, spatial distribution from 2007 to 2016.

\section{Sampling methods and sample size}

A total of 3393 sera samples were observed from records of sheep, goat and cattle population in River Nile, Khartoum, Gezira, White Nile, Blue Nile and Sennar states by non-probability multistage cluster sampling method choosing state as stratum and within stratum animal species were selected conveniently as a sampling unit based on presence and absence status of Rift Valley Fever.

\section{Detection of RVF Antibodies using ELISA}

Enzyme Lined Immunosorbent Assay (ELISA) was used according to manufacturer's instruction to detect RVF antibodies in tested sera from sheep, goat and cattle.

Retrospective study design was carried out to investigate spatial and temporal distribution from 2007 to 2016. ArcView software was used to reproduce the distribution of geographic maps.

\section{Statistical analysis}

ArcGis software version 10.2 was utilized to reproduce geographical maps for investigation and surveillance of the spatial distribution of Rift Valley Fever in the Sudan. Descriptive statistics, univariate analysis was utilized to determine risk factor associated with RVF seroprevalence by using SPSS version 20. 0.4.

\section{Results}

\section{Geographical and temporal patterns}

Seroprevalence of Rift Valley Fever using ELISA for cattle was $0.7 \%(n=137052), 0.1 \%(n=128113), 0.2 \%(n=1625), 0.01 \%(n=$ $126414), 0.01 \%(n=8316)$, and $0.2 \%(n=447655)$ in River Nile, Khartoum, Blue Nile, White Nile, Sennar and Gezira states respectively, while in goats was $0.07 \%(n=153151), 0.05 \%(n=64380), 0.2 \%(n=99168), 0.1 \%(n=21159), 0.6 \%(n=1005284)$ in River Nile, Khartoum, White Nile, Blue Nile, Gezira states respectively and in sheep was $0.1 \%(n=42134), 0.03 \%(n=267089), 0.25 \%(n=307449), 0.09 \%(n=40530)$, $0.08 \%(n=28348), 0.31 \%(n=257333)$ in River Nile, Khartoum, White Nile, Blue Nile, Sennar and Gezira states respectively(Fig. 2,3, and 4).

\section{Risk factor analysis in selected states}


In univariate analysis, locality and species were significantly associated with seroprevalence of RVF (P-value < 0.05), Where animal population was not in Gezira state. In Sennar and Blue Nile, species were found to be statistically associated with seroprevalence of RVF (P-value $>0.05),\left(X^{2}=3.879\right)$ and $\left(X^{2}=22.959\right)$ respectively. While locality and Animal population were not associated. In White Nile state, locality and animal population were highly statistically associated with RVF seroprevalence $(P$-value $>0.05),\left(X 2_{=} 76.034\right)$ and $\left(\chi^{2}=29.507\right)$ respectively, while species was not. Whereas, in Khartoum state, locality, species and animal population were not statistically associated with RVF seroprevalence (P-value <0.05) (Table 3).

\section{Environmental risk factors}

The study was shown significant difference between annual temperature and rain fall and RVF occurrence in Kosti, White Nile state $(P<$ 0.05), with (t-test $=-81.213)$, (t-test $=2.444)$ respectively. Also, annual temperature had significant difference with RVF occurrence $(P>$ 0.05) (t-test= -89.352), while rain fall has no significant difference $(P>0.05),(t$-test $=0.314)$ with mean value of $(28.869)$, $(286.083)$ in Madani, Gezira state. In Sennar state, annual temperature and annual rain fall were significantly different with $(P<0.05)$, $(\mathrm{t}$-test $=-79.746)$ and (t-test $=5.725)$ respectively (Tables 1,2 and 4$)$.

Table 1

temperature, relative humidity and rainfall and their association to RVF in White Nile

\begin{tabular}{|lllll|}
\hline Selected state & Year & Temp $\left(\mathbf{C}^{\circ}\right)$ & Relative humidity (\%) & Rainfall(mm) \\
\hline White Nile & $1973^{* *}$ & 29.5 & 13.6 & 382.0 \\
\hline $1977^{* \star}$ & 28.5 & 12.8 & 358.5 \\
\hline 2007** & 29.2 & 21.0 & 602.1 \\
\hline $1984^{*}$ & 30.2 & 3.9 & 96.0 \\
\hline $1988^{*}$ & 29.0 & 13.7 & 387.2 \\
\hline $1996 *$ & 28.6 & 15.0 & 423.6 \\
\hline
\end{tabular}

Subscription, ${ }^{* *}$ confirmed cases of RVF, * suspected cases of RVF in White Nile state

Table 2

temperature, relative humidity and rainfall and their association to RVF in Sennar

\begin{tabular}{|lllll|}
\hline Selected state & Year & Temp $\left(C^{\circ}\right)$ & Relative humidity (\%) & Rainfall(mm) \\
\hline Sennar & $1984 * \star$ & 29.1 & 1.72 & 174.7 \\
\hline $1988^{* *}$ & 28.1 & 1.68 & 580.7 \\
\hline $2007 * *$ & 28.3 & 1.69 & 773.9 \\
\hline $1996 *$ & 27.8 & 1.67 & 562.6 \\
\hline $2000 *$ & 28.6 & 1.70 & 550.9 \\
\hline $2003 *$ & 28.9 & 1.71 & 419.1 \\
\hline
\end{tabular}

Subscription, ${ }^{* *}$ confirmed cases of RVF, * suspected cases of RVF in Sennar state

\section{Riskanalysis for Rift Valley Fever}

In some scenarios, Sudan is exporting livestock and livestock products to the neighboring countries; however, until 2007, there was a directive from Sudan central bank that $20 \%$ of loan issued by the commercial bank to be directed to export sector. Therefore, improvement and preparation of veterinary services status and facilities, health situation of animals, availability of holding grounds, fed lots and quarantine stations to control RVF occurrence were estimated to be necessary. The impact or consequences of RVF occurrence was based on how far the impact could harm the livestock industry or public health. After year 2000 outbreak of RVF in Saudi Arabia, exports had generally decreased significantly in east of Africa including Sudan(1).

Risk estimation of RVF in Sudan 
The likelihood of RVF to occur in Sudan is likely to occur, however, there is free zone from the disease.

Export risk analysis

RVF is unlikely to happen in the Sudan at this scenario, in condition for exported livestock that are vaccinated against RVF, quarantined with veterinary certification before its consignment to importing country.

Import risk analysis

In this scenario, RVF is likely to occur through livestock and livestock products that are carrying RVFV from endemic country to Sudan without consignment regulation for heath and veterinary certifications.

In case of suspicion in RVF, surveillance for the disease by epidemiologists in relevant units in Animal Health Epidemiological Disease Control Directorate is carried out to investigate the suspected cases or outbreak. Also, field investigations are routinely done as a project designated to investigate and provide epidemiological data for priority disease e.g. RVF. There is a program for autumn diseases; whereas water associated diseases are investigated. The program is including health and veterinary situation in states. In addition, there are projects for entomological control, extension and preparation for field teams for rapid intervention.

In 2007, one outbreak of RVF in White Nile had reported to OIE by official of Federal Ministry of Animal Resources. Total animals affected were (110) cattle and (400) sheep in Zealot, White Nile. Epidemiological investigation has revealed that vectors were the main source of infections and vaccination was decided as control for the outbreak, beside other measure such as movement control inside the country , screening, Dipping or /and spraying of vectors or parasites, quarantine and treatment of affected animals. Sample was sent to Central Veterinary Research Laboratory (CVRL), (Soba) for diagnosis with Enzyme-Linked Immunosorbent Assay and the test was positive for RVF antibodies presence and for confirmation samples was sent to OIE Reference Laboratory, Onderstepoort Veterinary Institute (South Africa). 
Table 3

Estimated prevalence and relative risk on livestock population at study site

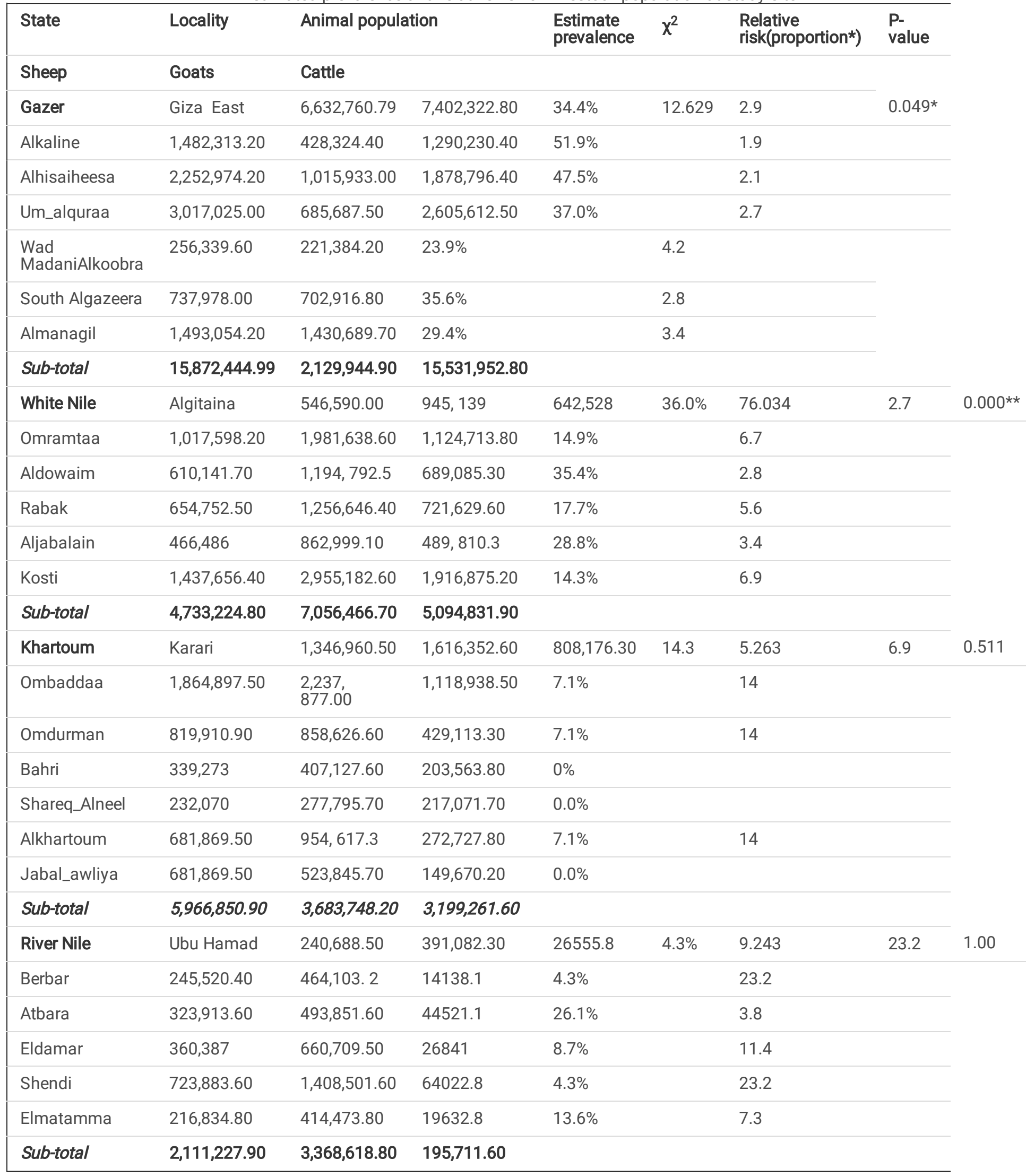


Table 4

Annual temperature and rain falls and RVF in selected areas

\begin{tabular}{|c|c|c|c|c|}
\hline Factor & & (Period of study/year*) & $\operatorname{Mean}(\mu)$ & Stud deviation(Sd) \\
\hline Predictive value & & 10 & & \\
\hline Annual temperature & & 10 & 0.252 & 0.004 \\
\hline Annual rain & & 10 & 0.319 & 0.126 \\
\hline \multirow[t]{2}{*}{ KOSTI } & Annual temperature & 35 & 29.163 & 0.7509 \\
\hline & Annual rain & 35 & 344.826 & 108.5063 \\
\hline \multirow[t]{2}{*}{ DUEIM } & Annual temperature & 35 & 29.660 & 1.2248 \\
\hline & Annual rain & 35 & 239.54 & 94.083 \\
\hline \multirow[t]{2}{*}{ MADANI } & Annual temperature & 35 & 28.869 & 0.5384 \\
\hline & Annual rain & 35 & 286.083 & 80.4990 \\
\hline \multirow[t]{2}{*}{ SENNAR } & Annual temperature & 35 & 28.391 & 0.6386 \\
\hline & Annul rain & 35 & 421.654 & 125.7245 \\
\hline \multirow[t]{2}{*}{ UMBANIEN } & Annual temperature & 35 & 28.743 & 0.7261 \\
\hline & Annual rain & 35 & 512.431 & 120.4924 \\
\hline \multirow[t]{2}{*}{ ABU NAAMA } & Annual temperature & 35 & 28.966 & 0.5477 \\
\hline & Annual rain & 35 & 570.091 & 111.1104 \\
\hline \multirow[t]{2}{*}{ DMAZIEN } & Annual temperature & 35 & 28.294 & 0.4589 \\
\hline & Annual rain & 35 & 691.426 & 106.8644 \\
\hline \multirow[t]{2}{*}{ KHARTOUM } & Annual temperature & 35 & 30.037 & 0.4923 \\
\hline & Annual rain & 35 & 124.174 & 74.0731 \\
\hline
\end{tabular}

* Correlation between RVF epizootiology and environment was confirmed by scaling up annual temperature and rainfalls for period of 10 year before and after 1976

\section{Discussion}

Rift Valley Fever is an arthropod-born zoonotic disease. It affects small ruminant's sheep and goats, cattle and camels can infected also human. Mosquito is principle vector of RVF. It follows heavy rain falls and characterizes by storm of abortion and high mortality rates and still birth in neonates and young animals. Rift Valley fever was confined to Africa and Madagascar and in year 2000 has occurred in Saudi Arabia and Yemen by (3) and (7). In this study, highest overall seroprevalence estimated for RVF was $0.7 \%$ in River Nile state, while lowest overall seroprevalence for RVF recorded was $0.01 \%$ in Khartoum and Sennar states. This was in agreement with study done to investigate spatial and temporal distribution or pattern of RVF from 1930 to 2007 in Tanzania by (8), whereas distribution of disease has been investigated by geographical information to understand its epidemiology at different areas and seasons. Also clustering had been reported in Gizera state, where foci or pockets of the disease were evident; this had come into consent with research done by (4), whereas clustering can estimate the incidence of RVF in study area for a certain period of time which provides understanding for the spatial and temporal distribution and epidemiology of RVF and provide explanation for circulation of the virus in certain region. In addition, annual temperature and annual rain fall were significant in all study area execept, rain fall was not significant in Gezira state, although this could be as a confounding factor.This was in agreement with report of RVF in Senegal and Mauritania by(6), where it associated with building of dam across senegal river and in Gezira is associated with Agricultural scheme and abundance of channels and irrigation system which considere abreeding site for mosquitoes the vector for RVFV .Also, altering of ecological condition was mostly contributing to distribution of RVF into new environment whereas humans and livestock at large were often exposed to get the infection with RVF. Eventually, early warning system was used to forecast and predict occurrence of RVF, satellite imagery were utilized to explore RVF in East africa. Before 
1976, susceptible cases for RVF were unknown, and could be mixed up with similar symptoms in differential diagnosis to other similar syndromes that cause hemorrhage e.g. wesselborn, pest des petites Ruminant virus, brucellosis Malaria, yellow fever, Anthrax, hemorrhage septicemia, (5) .In addition, sentinel herds were in use to monitor exposure for susceptible hosts and identify potential vector for RVF. Records, documentation and longitudinal data were useful tools for studying epidemiology of RVF. This report is important to understand the risk factors associated with RVF in sudan, in spite of further studies were required to fully investigate it.

\title{
Conclusion
}

The current study has concluded that RVF is endemic in some areas of sudan; and further surveillances is needed to throughly understand the dynamic and epidemiology of the disease. Also more epidemiological tools were emphasized to investigate the determinants of the disease in the sudan and to estimate the cost effective measurments of prevention and control of the disease.

\section{List Of Abbreviation}

\author{
RVF Rift Valley Fever \\ RVFV Rift Valley Fever Virus \\ ELISA Enzyme Linked Immunosorbent Assay \\ OIE Office international des Epizootique \\ CVRL Central Veterinary Research Laboratory \\ $\mathbf{C}^{\circ} \quad$ Celsius \\ Mm Millimeter
}

\section{Declarations}

This research work is declared to be done as a part of a partial fulfillment of requirement of doctoral degree

\section{Acknowledgement}

the authors of article would like to acknowledge the Director of Central Veterinary Research laboratory for permission to publish this research.

\section{Legend of supplementary material s}

Estimated prevalence of RVF in cattle

Estimated prevalence of RVF in goat

Estimated prevalence of RVF in sheep

\section{Ethical Approval and Consent to participate}

It is not in human data (retrospectively registered)

\section{Consent for publication}

The director of Animal Resource Research Corporation has accepting to publish this research work.

\section{Availability of data and materials}

Yes, the supplementary material of this research work is available for authors and not included in the text 
There is no conflict of interest from among authors to publish this research work

\section{Funding}

Ministry of science and Technology had been chosen as funder from the provided list at the editor manager

\section{Authors' contributions}

Manuscript writing and statistical analysis done by Mohammed Elsadig. Mansour ${ }^{1}$, information and data and bench work for laboratory diagnosis offered by Tamador Mohamed. Abdellah ${ }^{1,2}$, geographical disease map designed by Selma Kamal ${ }^{3}$ project proposition and guideline and revision on manuscripts done by; Atif A Abdelgadir ${ }^{4}$

\section{Acknowledgements}

the authors of this research work would like to acknowledge the Director of Central Veterinary Research laboratory for permission to publish this research done.

\section{Authors' information}

1 Central Veterinary Research Laboratory, Rift Valley fever unit Sudan 2 Central Veterinary Research Laboratory, Viral vaccine production Department, Sudan3 Central Veterinary Research Laboratories, Trypansomaisis Department, Sudan 4University of Khartoum, Faculty of Veterinary medicine, Department of Veterinary medicine and public Health, Sudan

\section{References}

1. Aklilu Y. An Audit of the Livestock Marketing Status in Kenya, Ethiopia and Sudan. Nairobi: African Union/ Interafrican Bureau for Animal Resources; 2002.

2. Daubney R, Hudson JR. Rift Valley Fever.The Lancet J, 1932.(1):611-612.

3. Elfadil AA, Hasab-Allah KA, Dafa-Allah OM. Factors associated with Rift Valley Fever in south-west Saudi Arabia. Rev sci tech Off int Epiz. 2006;25(3):1137-45.

4. Gadha S. A retrospective analysis of the epidemiology of Rift Valley Fever in Namibia. dissertation submitted to the Department of Veterinary Tropical Disease, Faculty of Veterinary Science University of Pretoria in Partial fulfillment of the requirement for degree ofMsc 2015.(Animal/Human/Ecosystem Health).

5. https://, accessed on 20.04.2020.

6. Jouan A, Adam. F, Coulibaly. I, Riou O,Philippe,B, Ledru E. (1990). Epidemic of Rift Valley Fever In the Islamic republic of Mauritanian.Geopraphic and ecological data. Bull. Soc. Path. Exot, (83): 611-620.

7. Jupp PG, kemp A, Grobbelaar A. The 2000 epidemic of RiftValleyfever in Saudi Arabia :Mosquitoe vector studies. Med. Vet. entomol, 2000. (16):245-52.

8. Sindato C, Karimuribo ED, Pfeiffer DU, Mboera LEG, Kivaria F. Spatial and Temporal Pattern of Rift Valley Fever Outbreaks in Tanzania; 1930 to 2007. PLoS. ONE 2014, (2): 9.

\section{Figures}



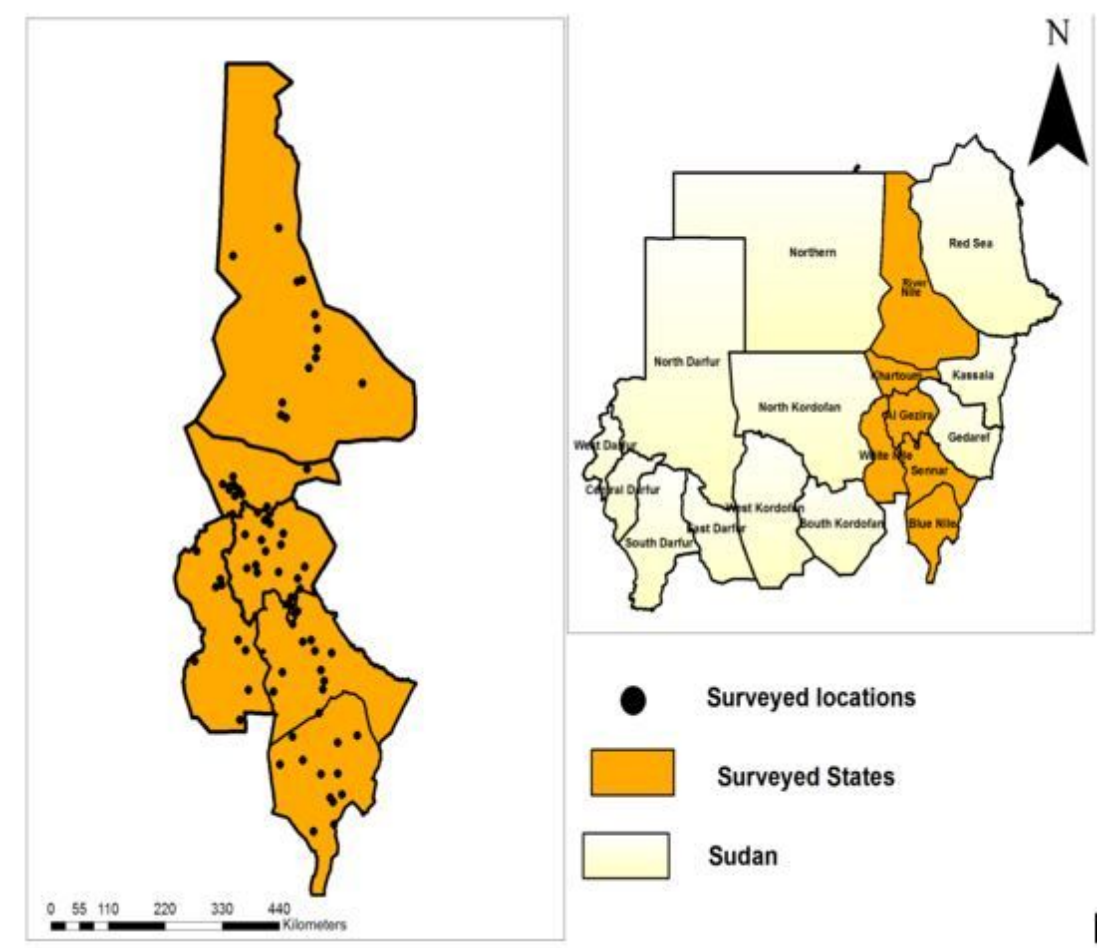

Figure 1

Geographical distribution for survey locations at study area.

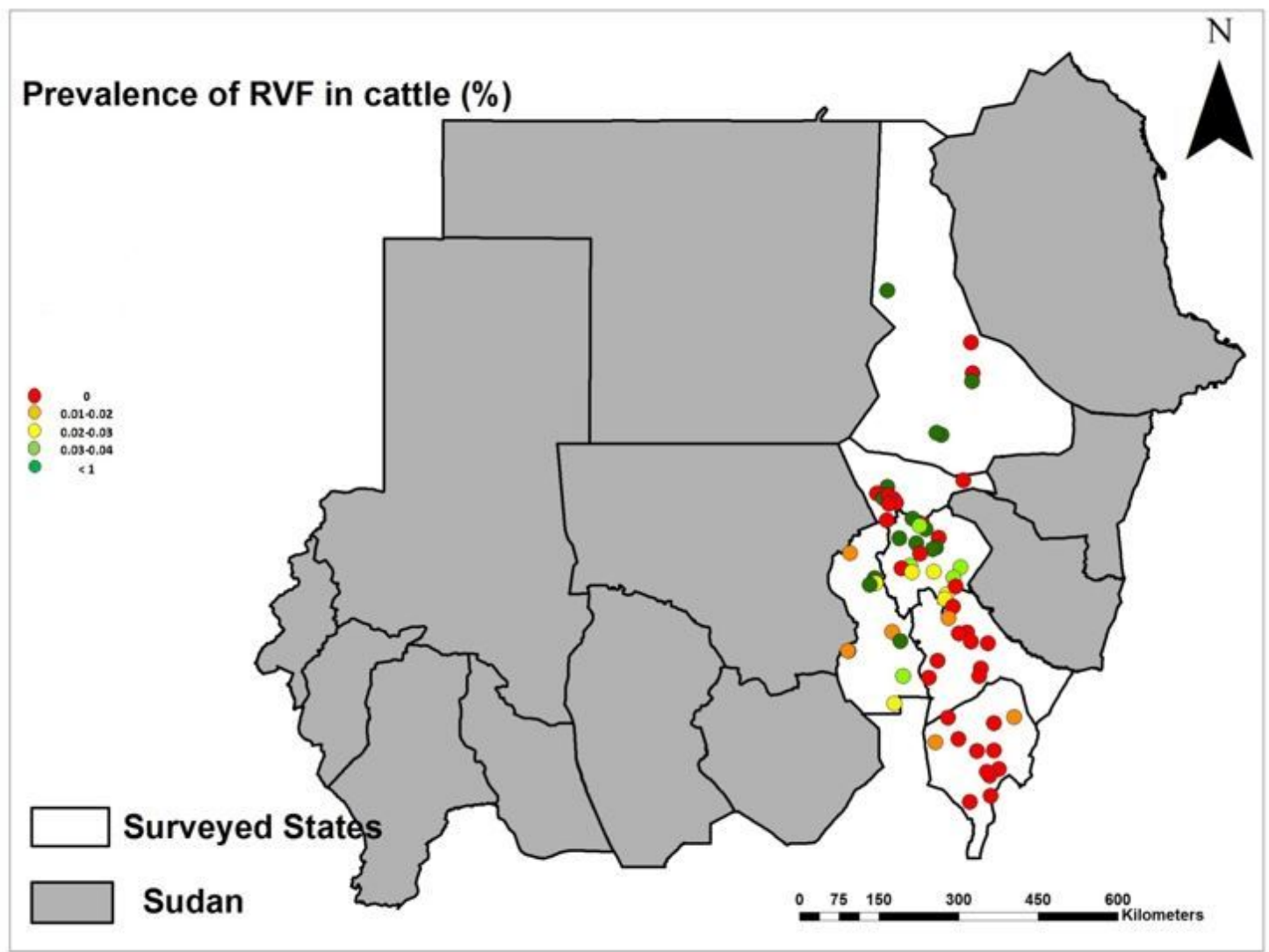

Figure 2

Estimated Prevalence of RVF in cattle 


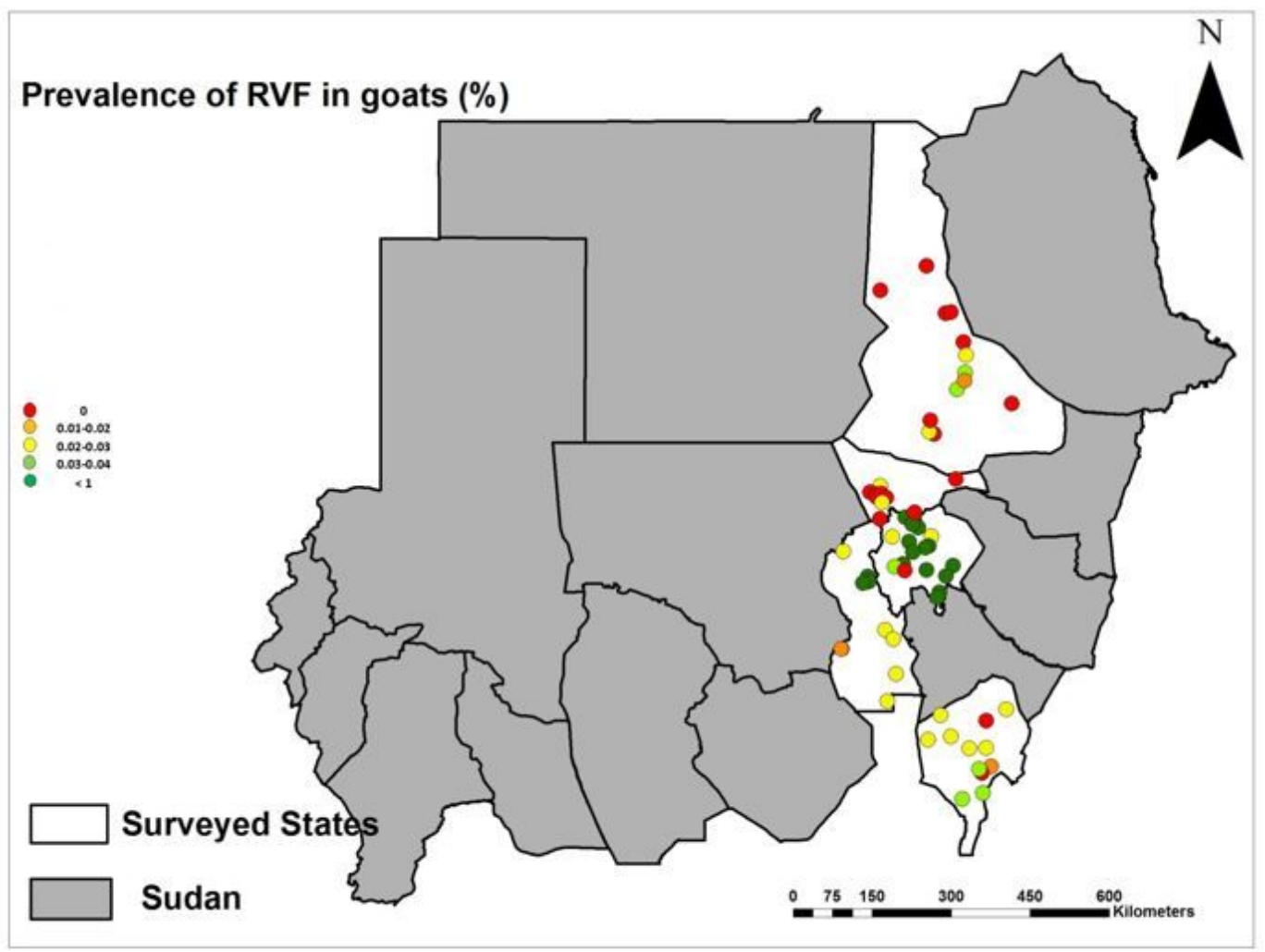

Figure 3

Estimated Prevalence of RVF in Goats

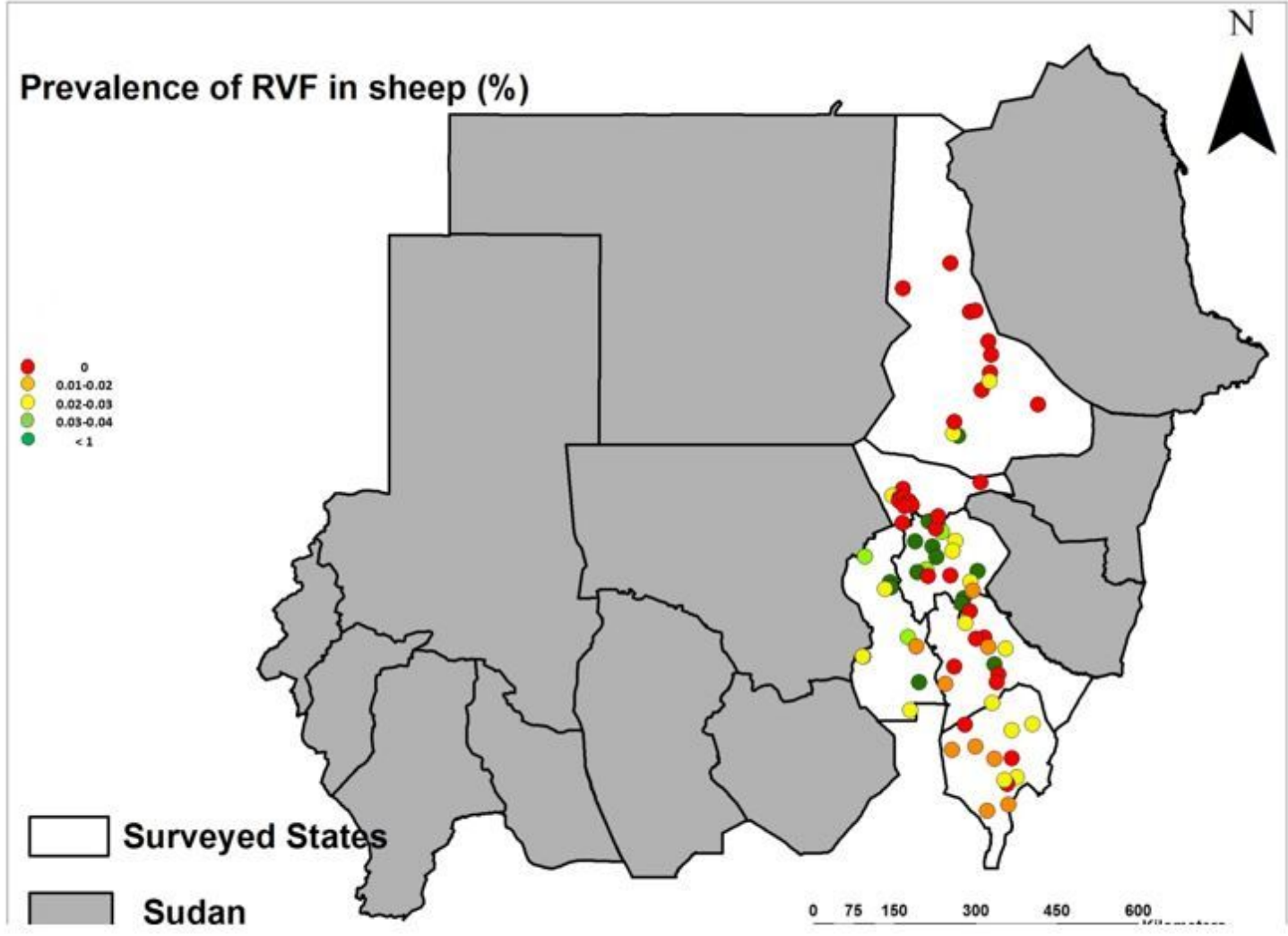

Figure 4 
Estimated Prevalence of RVF in Sheep

\section{Supplementary Files}

This is a list of supplementary files associated with this preprint. Click to download.

- RVFdatabas20072008Cattle.xlsx

- RVFdatabas20072008goat.xlsx

- RVFdatabas20072008sheep.xlsx 